\title{
8 The many facets of procedural justice in legal proceedings
}

\author{
Emanuela Ceva
}

\subsection{Introduction}

After spending a night drinking in a bar, a young woman named Sarah is gangraped by three men. Although the rape occurs in front of a cheering crowd, no one besides the victim is willing to testify. Therefore, before the case goes to court, the prosecuting attorney and the defence lawyers bargain, and the three rapists plead guilty to the assault. The sentence imposed for an assault charge is similar to that standardly imposed for rape. However, given the guilty plea, the victim is prevented from presenting her own story before a jury. This course of action leaves Sarah distraught and enraged. ${ }^{1}$

What went wrong in the criminal proceedings that can account for Sarah's reaction? To be sure, we can start from the conjecture that, by her reaction, Sarah claims that justice was denied to her. The formality of this initial conjecture calls for an analysis of what it means to do justice to the victim of a crime in legal proceedings. It requires, in other words, that we disentangle the many facets of procedural justice in this context.

To move forward, consider due process as an epitomic instantiation of procedural justice in legal proceedings. I devote this chapter to the presentation and discussion of three possible ways in which we can make a normative assessment of legal proceedings in the context of criminal trials. Two interpretations are quite customary in the philosophical debate and they both locate the value of due process in some external good to which criminal proceedings relate. The first account is instrumental and offers an 'epistemic interpretation' of due process as valuable because (and to the extent that) it allows for the truth of the matter to be revealed through the criminal trial. The criminal proceeding is thus valuable because it is causally related to reaching a 'just' verdict, one that declares the defendants guilty of the crime they have actually committed. Because there is no guarantee that this outcome will be reached on all occasions, the criminal proceedings, informed by due process, are an instance of what John Rawls (1971) dubbed 'imperfect procedural justice' (pp. 85-86). The second view comes from the 'expressivist interpretation' of the value of due process. In this interpretation, due process is a means to convey to the parties a certain message. On this view, criminal proceedings that instantiate the principle of due process are valuable because they contribute to the

DOI: $10.4324 / 9780429317248-12$ 
display of an appropriate consideration of the alleged victims and perpetrators. Under the 'expressivist view', justice thus resides in there being a vehicle for the public acknowledgement of persons' status - an ideal function that the proceedings may or may not be capable of achieving in practice.

Alongside these received interpretations, I want to suggest a third way of valuing due process. Besides their role in securing some kind of external good (establishing the facts or conveying a certain institutional consideration of the parties), the procedures according to which the different parties interact in legal proceedings can be considered inherently valuable and an object of normative assessment in their own right. In this 'interactive interpretation', due process has a specific 'constitutive value', which is realised ipso facto by the establishment of proceedings that instantiate it. This value consists in its capacity to change the parties' normative status by establishing them as the holders of rights and the bearers of duties that they would not otherwise have. ${ }^{2}$ Because criminal proceedings thus create, by their very establishment, deontic relations, they can be more or less just in themselves depending on their structural features but independently of their results. My final claim will be that to bring this third way of valuing due process to the fore is essential to rendering a complete picture of how procedural justice can be realised through and in legal proceedings (thus offering a full account of what goes wrong when a party is denied a procedural right, as was the case with Sarah's right to be heard in court).

\subsection{The instrumental value of due process}

\subsubsection{The epistemic interpretation}

According to a well-established instrumental approach to the normative assessment of legal proceedings, the importance attributed to the principle of due process derives from an epistemic interpretation of its value: ${ }^{3}$ When we look at criminal trials from this point of view, the proceedings are just to the extent that they are structured in a way that facilitates the revelation of the truth. Criminal proceedings are just, in this epistemic sense, only because and when they work as effective instruments in making sure the defendant is declared guilty only if he has actually committed the crime of which he is accused.

However, the eventuality that legal proceedings may fail to deliver an epistemically accurate result makes them an instance of what Rawls (1971, pp. 85-86) has famously characterised as 'imperfect procedural justice'. ${ }^{4}$ For Rawls, procedural justice is perfect, when we have a process capable of leading to the just outcome with certainty. Crucially, what constitutes a just outcome is known even before we engage in the process, and the process is in fact devised in entirely instrumental terms towards said outcome. ${ }^{5}$ In the case of criminal proceedings, we have seen that a just outcome is one that meets the epistemic standard of declaring the defendants guilty only of the offence they have actually committed. But it is apparent that there is no guarantee that a specific procedure can be devised that constantly delivers such an outcome (Rawls 1971, p. 85). ${ }^{6}$ 
The imperfect nature of the kind of procedural justice that the epistemic interpretation of the value of due process instantiates can be usefully employed to make sense of one facet of the distressed and enraged reaction of the victim of rape in our example. From this epistemic point of view, it seems inevitable that Sarah was enraged and distraught by the negotiated outcome of the proceeding. While the prison sentence for assault is similar to that usually imposed for a rape, the fact that Sarah was raped was not at all established, and therefore the proceeding by which the sentence was reached cannot be considered just on the grounds that it failed to deliver an epistemically accurate outcome. The victim was not offered reparation for the actual offence she had suffered.

This instrumental interpretation can thus make sense of one important dimension of the normative assessment of criminal proceedings. In the epistemic interpretation, criminal proceedings are unjust if they fail to lead to a legal decision that is appropriately responsive to the facts in question, as was the case with Sarah's rape. Notice that the normative source of the value of the criminal trial is external. This means assessing the proceedings in view of their being causally related to reaching a decision whose value (being respondent to the truth of the matter) pre-exists the proceedings and their development. We can thus see how the proceedings are valued to the extent that they are subservient to the achievement of that decision.

While this epistemic aspect is important in the normative assessment of legal proceedings, I want to show that it is not sufficient. It cannot give a full account of how those proceedings may be more or less just, nor can it offer a solid defence of the value of due process. This is because in the epistemic interpretation, due process is entirely fungible. Consider the critical discussion Richard Arneson has offered of the legal procedural rights enjoyed by defendants and implied by the principle of due process. These procedural rights include 'the right to confront one's accusers, the right to a speedy trial, the right against self-incrimination, the right to counsel, the right to a jury of one's peers, and so on'. Arneson (1993) argues that,

this panoply of rights would dissolve if it were discovered that abrogating them wholesale would produce trial verdicts that are fairer (and generate no morally undesirable outcomes of such magnitude as to outweigh the increased fairness of trial verdicts).

So, Arneson concludes, given the imperfect nature of criminal proceedings informed by the principle of due process in delivering justice, were we to find more effective instruments to establish the truth of the matter about a crime, we should abandon due process without any regrets. In response to Arneson's challenge, we could easily point out an implausible implication of his argument. If we claimed that procedures are inherently irrelevant from a moral point of view (because they are mere fungible instruments to deliver justice), we should be prepared to accept that any procedure enhancing the accuracy of criminal trials 
should be preferred to a criminal trial guided by the principle of due process, even if that implied torturing the defendant to establish the truth of the matter. But who can possibly be willing to bite this bullet? Arneson is not and, in fact, he has a response to such a rejoinder:

The idea that procedures should be chosen in order to attain morally best results does not mean that the immediate consequences of operating the procedures themselves should be excluded from calculation ... My position is that there are no special procedural rights determinable by examining our intuitions about inherently fair procedures (supposed to be independent of our convictions about the substantively fair outcomes that procedures work to reach) ${ }^{7}$

(Arneson 1993, p. 121)

Arneson's line of argument is successful in showing that when we engage in the normative assessment of a criminal proceeding (just like any other process) we must also consider the impact the operation of such proceeding has on those who participate in it. This point is, in fact, empirically corroborated by a vast body of literature on the social psychology of procedural justice (see Tyler 1988, pp. 103-135; Thibaut \& Walker 1975; Napier \& Tyler 2008, pp. 509-510). This literature shows that the participants in any given process are psychologically more inclined to recognise the outcomes of that process as fair when they feel they have been treated fairly in the process itself even if the outcomes are not in their favour. This inclination is likely due to the positive effects that the participation in a fair process has on the parties. For example, the feeling of being respected when participating in a process where one has the opportunity to speak up and be heard, may enhance self-respect and encourage participants towards a more positive assessment of the fairness of the outcome. ${ }^{8}$ I shall expound this thought in the next subsection.

It bears highlighting now that these psychological findings lend empirical support to the twofold limitations of the epistemic interpretation I have mentioned above. First, the epistemic value of due process - while weighty and importantis not exhaustive of the considerations that matter for a complete normative assessment of legal proceedings. We should also, at least, consider the effects that the participation in a process has on the parties in it. Second, in order to offer a solid account of the value of due process, we should pinpoint the features of the process that make it inherently worthwhile, beyond its extrinsic appreciation as a fungible instrument of epistemic justice.

\subsubsection{The expressivist interpretation}

To address the limitations of the epistemic interpretation of the value of due process in legal proceedings, I want to present a second received interpretation. This further interpretation also points to an external good as the source of the value of due process, but it also assesses legal proceedings in virtue of their capacity to 


\section{Emanuela Ceva}

convey to the parties a certain message with respect to that good. Notably, in this interpretation, the good in question is the appropriate consideration of the status of the alleged victims and perpetrators, which must be publicly displayed. The justice of the criminal trial thus resides in its contributing to the acknowledgement of persons' status in a specific legal context. This acknowledgement is often deemed important because of the impact it is expected to have on the parties' self-perception, particularly their self-esteem.

To see the rationale of this expressivist interpretation of the value of due process, I proceed by analogy with what Charles Beitz (1989) termed the idea of 'fairness as equal respect'. ${ }^{9}$ Beitz's idea is straightforward: The way citizens are treated by the procedures through which they interact in society reveals the consideration institutions have of them. Take the case of democratic egalitarian decision-making procedures. The democratic way of making collectively binding decisions bears an expressive value because it is the way in which institutions display their public recognition of the status of citizens as equal political agents. ${ }^{10}$ On this basis, Beitz (1989, p. 23) argues that just democratic decision-making must be perfectly egalitarian. This feature is necessary to ensure that all citizens' interests are taken into due consideration, which, in turn, is expected to have a positive impact on their self-esteem.

Taking the cue from this expressivist assessment of the democratic decisionmaking process, we can translate the same line of reasoning into an expressivist interpretation of the value of due process in criminal proceedings. In this interpretation, the value of due process is irreducible in full to its instrumental capacity to produce just outcomes, that is legal decisions that establish the facts. Legal proceedings informed by the principle of due process retain their value even when judicial errors taint their outcomes insofar as their operation conveys to people important institutional messages whose public expression might also have a positive impact on the parties' self-perception. This expressivist interpretation seems to pinpoint an important normative dimension of criminal proceedings that was clamorously frustrated in the case of Sarah's rape. By pleading guilty to assault, the rapists were not publicly recognised as such (that is, as the perpetrators of the brutal offence Sarah had actually suffered). Correspondingly, by that sentence, Sarah was not recognised in her status as a victim of rape, thus diminishing her status as the sufferer of a horrendous crime with a negative impact on her sense of self-worth. But most significantly, by not being offered the opportunity to tell the story in her own voice before a jury in court, we can see that she was denied the procedural status as the bearer of a reliable testimony of her own story. This denial is a source of injustice because it expresses a diminished consideration of Sarah's standing in the legal proceeding, which is likely to have a negative impact on Sarah's sense of self-worth and hence her reaction of distress and rage.

Including the expressivist value of due process in our normative assessment of legal proceedings is an important step towards offering a fuller account of the relevant considerations necessary to perform a well-rounded and nuanced evaluative exercise. It is, therefore, a significant improvement over the use of only the 
instrumental kinds of assessments that the epistemic view enabled us initially to do. However, I wish to suggest that the capacity to appreciate the complexity of the normative worth of legal proceedings can be further enhanced. This enhancement, in line with the thread of the argument followed in the previous subsection, should be capable of offering a solid account of the value of due process-more solid than one consisting in its appreciation as a fungible instrument of justice.

When the expressivist interpretation refers to the positive impact that the participation in a certain process may plausibly have on people's self-perception, it is exposed to erratic empirical considerations. The expressivist interpretation establishes a relation between the operation of certain criminal proceedings and the realisation of some moral values such as self-respect and self-worth. It is important to notice that this relation is mediated, extrinsic and contextual. The relation is mediated by the psychological effects that the participation in a certain process can be expected to have on the parties in that process. It is extrinsic because it draws substantially on certain mental states and attitudes that are external to the structural features of the process itself (although it is crucial to acknowledge that personal mental states and attitudes and the process's structural features are causally related). Finally, the relation between due process and justice is contextual because it is clearly conditional on the empirical verification of the abovementioned psychological effects and the realisation of the related mental states and attitudes, which may or may not occur. Quite plainly, different people can plausibly be expected to react differently to the same events, given their own inclinations and states of minds. ${ }^{11}$ It is little more than a truism to notice that what is deeply humiliating for one sensitive human being, may be just a mild offence for another.

Further, people may develop complex sets of adaptive preferences that make it impossible to predict how they are going to react to contextual stimuli and institutional treatment. ${ }^{12}$ To complicate the picture further, these variations are personal as well as cultural, and they may be subject to influence by historical developments too. How can we say that Sarah is just not overreacting to a perfectly acceptable bargained solution? Had she not been incensed, out of timidity or indifference, would that be a reliable basis not to question the justice of the legal proceeding denying her a fair hearing at all?

I think these are important questions to address to advance the refinement of our normative assessment of legal proceedings and understanding of the value of due process within that context. My claim, which I elaborate in the remainder of the chapter, is that to run a complete normative appraisal of the properties of criminal proceedings and offer a solid account of the value of due process, we should pinpoint the procedural features that make processes inherently worthwhile. To appreciate the normative powers the mere participation in a process constitutively confers upon the parties, it is essential to engage in a structural analysis of the inherent properties of that process. This analysis, I will submit, is also crucial to see the normative statuses, which the parties acquire just by virtue of their participation in the process. 


\subsection{The inherent value of due process: the 'interactive interpretation'}

\subsubsection{The different sites of the justice of a process: outcomes and procedures}

The idea I want to present in this second part of the chapter is that the procedures according to which the different parties interact make a third important contribution to any normative assessment of a criminal trial. Besides their instrumental role in leading to an epistemically accurate final verdict, and besides their contribution to expressing certain positive institutional attitudes, procedures informed by the principle of due process can be considered inberently valuable by virtue of their structural properties. ${ }^{13}$

To articulate this idea, a good place to start-ad absurdum-is Martha Nussbaum's (2006) critical discussion of procedural justice. With some irony, Nussbaum, argues that the idea that substantive value may lie in the structural properties of a process (rather than entirely in its outcome) should be rejected because it sounds

as if a cook has a fancy, sophisticated pasta-maker, and assures her guests that the pasta made in this machine will be by definition good, since it is the best machine on the market. But surely ... the guests want to taste the pasta and see for themselves.

(Nussbaum 2006, p. 83)

Surely enough, Nussbaum's critique exposes a weak spot of a certain mainstream view of procedural justice that conceives it, in Rawls's terms, as a pure exercise of formality, by virtue of which having a just process is both necessary and sufficient to securing a just outcome. ${ }^{14}$

Central to Rawls's idea of pure procedural justice is the claim that procedures are capable of transferring the justice of their properties to their outcomes (Rawls 1971, p. 86). ${ }^{15}$ So, it is sufficient to have a just procedure and apply it correctly for the justice of its outcome to be secured. This idea, which Rawls had formally illustrated with reference to a procedure of fair bets, has become very popular in the characterisation of the authority of the democratic decision-making process (see Christiano 2008; Waldron 1999). The idea is that because there is disagreement over what a good or just collective decision is on many politically relevant issues, we must ensure that whatever decision is taken that decision is at least legitimate, that is, recognised as binding by all citizens (including, of course, those who disagree with its content). To this end, the resort to pure proceduralism is based on the conviction that if we get citizens to agree on the legitimacy of the decision-making process, they would ipso facto recognise the legitimacy of the outcomes of that process (even if they could question them as inherently bad or unjust).

As argued extensively in previous work (Ceva 2016, pp. 71-73), pure procedural justice is in fact the formal property of the outcomes of a process. We need 
just procedures not because having them (or making them operative) realises any distinctive dimension of value per se. We need just (or legitimate) procedures only to identify acceptable outcomes in circumstances of moral disagreement. Whatever outcome has the formal property of being produced by a just (or a legitimate) procedure is, in this view, itself just (or legitimate) or, at least, not unjust (or not illegitimate). Nussbaum's example suggests the inconsistency of this interpretation of proceduralism by questioning the inference from the qualities of procedures to those of their outcomes. Of course, to question this inference does not mean to undermine the practical possibility that people may decide to agree between themselves to abide by the outcome of a process, whatever this outcome will happen to be. Not only are we familiar with this commitment within democracies, but also anytime we toss a coin to make a decision or participate in a lottery we engage in an exercise of pure proceduralism. However, the familiarity with these practical occurrences does not justify, nor does it entail, the philosophical claim that the normative properties of an outcome may be inferred from the normative properties of the procedure that produced it. As Nussbaum's example suggests, the claim that we can identify the justice of an outcome with its formal correctness is fallacious. Processes and outcomes are distinct social objects, and recognising the justice of one tells us nothing about the justice of the other (see Ceva 2016, p. 74).

But there is an important 'but'. In my previous work in the domain of justice (Ceva 2016, Chapters 3 and 4), I introduced a claim about the normative assessment of the structural properties inherent to processes, which lies beyond Nussbaum's critical target. This is the claim that procedures and outcomes are distinct sites of justice; therefore, they can and should be assessed in the light of distinct normative standards. The way in which I see this claim is actually quite crude: in assessing the normative force of processes of human interaction (in the domain of justice), what matters is not only what people get, but also how they get it. While the former kind of assessment concerns the normatively relevant properties of the outcomes of a process, the latter concerns the structural properties inherent to the process itself. When we assess a process from this latter perspective, we focus on its inherent structural properties and the form of interaction they establish among the participants in the process. In this sense, processes (and the normative principles that inform them) may also have an 'interactive value'.

To see what the interactive value of a process is, start from the simple notion of a process as a rule-based embodied practice. ${ }^{16}$ From this point of view, to offer a full characterisation of a process and a complete assessment of its properties, we must consider the formal rules that articulate the process but also what happens when people enter the process and have their dealings regulated by the rules of that process. Differently put, to characterise and assess a process, we must look at what changes occur to the status of the participants in the process and their reciprocal relations by virtue of the process's rules. Notably, the rules on which a process is based establish the participants in the process in a new normative capacity that does not exist prior to or outside the process. The participation in a process confers-ipso facto-special normative powers to the participants in the process. 
That is to say, the rules of the process establish what people who participate in the process can claim against and owe to each other when they interact within the boundaries of those rules. In this sense, processes can be usefully understood as practices based on 'constitutive rules'.

John Searle $(1969,1995)^{17}$ has offered the best-known account of the idea of a constitutive rule. Constitutive rules establish new practices and make them possible. These practices instantiate forms of action and relations that could not occur, nor could they be conceived, prior to or outside those rules. Rawls outlines the same view in the parlance of a 'practice conception' of rules (1955). According to this conception, rules define practices. To make people engage in a practice, the rules that define the practice (and on which the process in which the practice consists is based) must be taught to them. This understanding of a practice makes rules logically prior to particular activities because an activity may be described in a certain way only if it takes place against a certain practice, in accordance with a process articulated through the rules that define that practice. A typical illustration of this practice-based understanding of a process and its constitutive rules comes from games (Searle 1969, p. 33). A group of people can kick a ball around a field and aim at throwing it in a net; but they cannot score a goal or commit a fault unless they engage in the practice of playing soccer. However, they cannot engage in the practice of playing soccer unless a process that articulates the rules of soccer is established. When someone plays a game, they must abide by its defining rules; otherwise, they are just not playing that game but engage in an altogether different kind of practice.

Interestingly for the purposes of my discussion, those who engage in a process, thus understood as a practice, start acting and interacting with others in a special capacity with which special normative powers are associated. To continue with the game-based illustration, someone's participation in a game of soccer as a player establishes and gives a special normative sense to what the partipants in the game do. By entering into the practice of playing soccer, players acquire special normative powers that derive from their status in the process. For example, any random person blowing in a whistle does not normally have the power to stop anyone else from running unless the relevant interaction happens within the process of playing soccer and the protagonists are the referee of the game and a player.

We can thus see how the constitutive rules of a process have two main normative functions. First, they establish people in certain statuses, and second they confer on them the powers linked to those statuses (see Hindriks 2009, pp. 254, 262). These normative powers establish deontic relations between their holders, as they constitute a form of interaction between right-holders and duty-bearers, which has an inherent value-what I have called an interactive value. To see this value, consider the way Joel Feinberg (1970, pp. 243-257) has brought this feature to light with admirable clarity. Feinberg invites us to imagine the society of Nowhereville, where rights do not exist. We can assume that even in such a society people might act according to justice and give each other their due, either by benevolence, because they all adopt some teleological principle of desert, or 
because some law or authority makes them do so. However, if rights were not in place, something important would be different from the rights-populated world we are used to: People would receive justice, but could not make claims as the final authorities to which justice is due.

The status of a claim-maker that the conferral of rights implies is importantly different, Feinberg (1970, pp. 244-245, 249-250) explains, from that of the beneficiary of some good because it entails the attribution and recognition of agency. Right-holders can claim against others that certain actions be performed (or omitted), and they are those to whom the others need to account for their behaviour toward them. The conferral of rights is thus importantly related to persons' moral standing or, to put it in Feinberg's words, 'having rights enables us to stand up like men ... to look others in the eye' (Feinberg 1970, p. 252). The establishment of rights is thus constitutive of an inherently worthwhile form of human interaction that could not occur outside the procedures in which those rights are exercised. We can thus start to see how the value of this form of interaction is inherent to the structural properties of the process through which this interaction occurs, and may not be reduced either to the value of its final results or the effects it may cause as it develops. To gain a better view, let us finally bring this general discussion to bear on the normative assessment of criminal proceedings.

\subsubsection{The inberent interactive justice of criminal proceedings}

The claim that the inherent structural properties of a process may have a value of their own-what I have called an 'interactive value'-does not hold true for any organised set of procedures. There are of course some procedures that are designed and made operative only as instruments to produce certain independently valuable outcomes. Think of the procedures of traffic regulation or, in fact, the instructions to operate a pasta-maker, to revisit Nussbaum's burlesque example. This apparent qualification granted, it is equally apparent that any one set of procedures in society can have more than an instrumental value (e.g. of the kind we have seen with reference to the epistemic view of due process in the first part of the chapter).

A conspicuous instance of a process that can have inherent interactive (as well as, as seen, instrumental) value, I want to suggest, emerges in consideration of the principle of due process in criminal proceedings. To engage in a normative assessment of criminal proceedings by bringing out the interactive value of due process means and requires concentrating on the inherent structural properties of the process and the moral values these structural properties realise in themselves. This kind of assessment is worthwhile, I believe, because it enhances our capacity for appraising the many facets of justice in criminal proceedings and presenting a theoretically solid account of the value of due process. This enhanced assessment may help us to ponder the extent to which we have reasons to value due process irrespective of whether the criminal trial informed by it leads to epistemically inaccurate verdicts or fails to express a message capable of eliciting the right kind of attitudes in those who participate in it. 
To see where the interactive value of due process lies, reconsider the case of the legal proceeding by which Sarah's rapists plead guilty to a charge of assault before the case could go to court. We have seen that Sarah was distraught and enraged at the end of this story, and we have already pointed out why that could be the case from an instrumental perspective. I want to suggest that besides the disappointment over an epistemically inaccurate verdict, and the sense of frustration derived from the lesser consideration of the offence she had suffered, Sarah's reaction can be seen as a manifestation of an interactive injustice she has suffered by not being heard telling her story in her own voice before a jury in court. Sarah's negative reaction speaks to the inherent moral importance of the structural properties of legal proceedings informed by the principle of due process, access to which was denied to Sarah by virtue of the agreement that was bargained before the case could be brought to court.

The right to a fair hearing that due process confers upon the participants in criminal proceedings changes the normative status of the victim and, thereby, the nature of what goes on between her and the perpetrators of the offence she had suffered. This change is important because it opens up new possibilities of action and interaction that would be impossible outside the process in virtue of the constitutive rules that define it. By being prevented from giving her own account of the facts, Sarah was denied the normative status of an agent speaking out in her own voice, as the holder of rights and as the potential maker of a valid claim. She was relegated to the role of a mere patient who passively receives both the offence and the sentence negotiated by others. This denial is not only problematic because it was an impediment to establishing the truth of the matter in court; nor was it wrong only because it is likely to have resulted in a loss of self-appraisal on the part of the accuser (thus misrecognised in her status as a victim). The frustration of due process was wrong in itself because it constituted a mistreatment of Sarah, a failure to do justice to her moral status as an agent capable of engaging in peer-interaction with her offenders. This enabling capacity is a typical feature of rights and the normative status their conferral bestows on their holders-the status of a claim-maker (or, an agent). As seen above, following Feinberg's characterisation, the conferral of rights by virtue of someone's participation in a rule-based process is importantly related to a person's standing. More precisely, the conferral of rights is constitutive of an inherently worthwhile form of human interaction that could not occur outside the procedures in which those rights are exercised.

The time has come to emphasise how this general feature of rights is realised in due process and how it gives inherent value to fair hearing as a structural feature of criminal proceedings modelled on that principle. I think that this idea can make sense of those views of due process that insist on its relation to the conferral of a certain kind of 'dignity' on the parties in criminal proceedings. So, for example, Jeremy Waldron (2013) seems to point at this feature when he argues that 'deciding what to do about a suspected offender is not like deciding what to do about a rabid dog or a dilapidated house' (p. 12). The parties' status must be reckoned with and adequate procedural provisions must be designed, whether 
these also contribute to truth-finding and boosting the parties' self-perception or not.

Within this context, Waldron (2013, p. 201) presents dignity as a status-concept, as it has to do with 'the standing (perhaps the formal legal standing or perhaps, more informally, the moral presence) that a person has in society and in her dealings with others'. ${ }^{18}$ So conceived, a person's dignity supervenes on her agential capacities to be the author of her own actions on the basis of her own account of herself and of 'the norms and reasons that apply to her' (Waldron 2012a, p. 202). In line with the Kantian tradition, possession of such capacities is the mark of moral personality; it is what makes people agents rather than mere patients, and what makes them act as subjects rather than merely undergo others' actions as an object. In this sense, this status as agents is a precondition for people to be considered as the bearers of rights, that is, of valid claims that each of them may stake against each other. When rights are established in certain processes, people can interact by participating in those processes in a way that gives them due consideration in their capacity as potential makers of valid claims.

Criminal proceedings informed by the principle of due process may rightfully be considered an instantiation of this form of interaction and have, therefore, also an inherent interactive value. The very idea that a person has a right to have her say on her own behalf before a public tribunal is a constitutive component of the treatment of a person in accordance with her status of claim-maker. But due process is not the only instantiation of this kind of value in legal proceedings. Waldron, for example, discusses in a similar vein Lon Fuller's account of 'selfapplication' in law. This is the idea that people comply with official legal provisions prior to the coercive intervention of law (see Fuller 1969).

An example is unsuccessful defendants in civil litigation, who are expected to pay by themselves what is ordered by the court or, in criminal justice, convicted offenders who are expected to report to prison on a given date. Clearly, should defendants fail to do what they are expected to do, the authorities would intervene (to seize the former's property or to escort the latter to jail); but-Waldron (2012a, p. 206) argues that the presence of provisions of self-application is to be viewed as an instantiation of a person's capacity for agency. This is the case, I add, irrespective of the possibly suboptimal implications such provisions may have for the effective and time-efficient application of the judicial decision.

The attribution of this moral status of an agent to the parties in legal proceedings, in general, and in a criminal trial, in particular, is not a mere side constraint on what can be done in courts while justice is pursued, while juries try to establish the truth and reach the right verdicts. This attribution and the forms of interaction thereby inaugurated between the parties are a structural feature of criminal proceedings that make them an object of normative assessment in their own right and in accordance with standards internal to their own functioning. Note also that the presence of procedural provisions treating persons in ways that protect them from humiliation and degradation is not only a symbolic matter, expressing the consideration in which institutions hold those who take part in them. The recognition of the moral status of an agent is not just expressed through 
procedural provisions, ${ }^{19}$ it is participation in the proceedings regulated by such provisions, which bestows this status upon the parties and enables them to entertain dignifying forms of interaction.

Finally, it is important to notice that the normative assessment that the adoption of this interactive perspective makes possible is not an alternative to, but an integration of the instrumental kinds of assessment I have reviewed earlier in this chapter. As my current discussion of legal proceedings shows, the normative evaluation of processes is a complex and composite exercise that requires the cooperation of many different evaluative criteria. All of these criteria should work in tandem to render an all things considered normative evaluation of a process that makes discrete assessments valid only pro tanto. The realisation of interactive justice in procedures is a necessary, but not sufficient, condition for the realisation of justice in politics, in society, and in legal courts (see Resnick 1977, p. 213). This normative approach to processes of human interaction introduces nuances that may complicate their assessment, but such complications are worthwhile because they make the evaluation of those processes more philosophically accurate.

\subsection{Conclusion}

In conclusion, one important result of the discussion in this chapter has been that, when we engage in the normative assessment of criminal trials (like any other process), no loss in one dimension of justice may be fully compensated by a gain in the other. The demand for interactive justice would remain valid even if we had omniscient and infallible juries capable of getting to the just outcome in all possible cases. The demand for interactive justice is a demand for being reckoned with as active subjects and not merely treated as the objects of others' actions. The attribution of this status bears an inherent value whose frustration makes a process inherently unjust, no matter how it could serve any other function.

\section{Notes}

1 Sarah is the leading role played by Jodie Foster in the 1988 film The Accused. (https://www.imdb.com/title/tt0094608/). I borrow the example from Miller (1999, pp. 97-98).

2 I have tentatively presented this idea in Ceva (2016), Chapter 3. This chapter revisits and expounds the thoughts therein introduced.

3 For a seminal account of the epistemic approach in political theory, see Estlund (2008); I have discussed this approach at length in Ceva (2012, pp. 192-194).

4 For a discussion of the plausibility of Rawls's typology of procedural justice see Nelson (1980, pp. 502-511).

5 To illustrate this kind of procedural justice, Rawls (1971, p. 85) provides this example: 'A number of men are to divide a cake: assuming that the fair division is an equal one, which procedure, if any, will give this outcome? Technicalities aside, the obvious solution is to have one man divide the cake and get the last piece, the others being allowed their pick before him. He will divide the cake equally, since in this way he assures himself the largest share possible'. For a critique of 
the tenability of the distinction between perfect and imperfect proceduralism, see Gustafsson (2004, pp. 300-305); the claim that Rawls's im/perfect account of procedural justice is indeed a form of 'proceduralism' is disputed by Rosenfeld (1998).

6 These versions of proceduralism are distinguished from what Rawls (1971, p. 86) calls 'pure procedural justice'. In this last idea, the qualities of a just outcome cannot be known before a just procedure is actually operated, and in fact the justice of outcomes depends entirely on the justice of the procedures leading to them. Once we operate a just procedure correctly, its outcome will be just whatever its inherent features. I will not engage with this interpretation here (but will revisit it below) because it is not relevant to the assessment of legal proceedings, which cannot of course be open-ended in the way Rawls thinks pure procedural justice should be. For an extensive discussion, see Ceva (2016, pp. 67-69).

7 For an in-depth discussion of Arneson's argument see Ceva (2012, pp. 196-197).

8 The centrality of the value of self-respect for procedural justice is at the core of the argument in Meyerson (2015).

9 Of course, this is one interpretation of the expressivist value of due process. A different way of framing the view would insist that the process is not just a mere means to convey a certain message but embodies or enacts the message. Two possible readings are available of this version of the expressivist view. One, as suggested above, would look at due process as enacting a message whose content is, nevertheless, valuable independently of the process. In this reading, for example, we could think that just criminal trials are those positively responsive to the moral dignity the parties have outside the proceedings (as persons) and that must be preserved in the process too. In this sense, the parties' status acknowledged in the process would be a reflection of a more general moral status that people have (as the external source of the value of due process). I view this version as exposed to the same limitations that I attribute to the view I discuss in what follows. On an alternative interpretation, the process would embody a message, which would confer (not just acknowledge) a certain normative status on the parties in the process. This further reading would be a game changer, as it were, akin to the position that I am going to defend in the second part of the chapter to which I refer for any further comment. I am grateful to the editors of this volume for pressing me on this point.

10 Recent statements of this position may be found in Christiano (2008) and Griffin (2003). For a general discussion of the position, see Elster (1999).

11 For a classic set of critiques of utilitarianism along these lines, see Sen and Williams (1982).

12 Jon Elster (1982, p. 237) has seminally characterised these preferences and preferences of the 'sour grapes' kind.

13 I have introduced this idea in the debate concerning just conflict management under the label of 'intrinsic proceduralism' (see Ceva 2016, pp. 74-79; 84-86; 99-107).

14 Formal accounts of procedural justice are presented, for example, in Hart 1961, pp. 155-157; Kramer 1997; May \& Morrow 2012. For a discussion, see Lyons (1973).

15 The steps towards the formulation of this idea of procedural justice can be traced back to Hobbes (1985, p. 14), and they have been developed after Rawls in, e.g. Hampshire (1999).

16 I take this conception to be well received in the philosophical debate on institutional theory-see, e.g., Emmet (1966); Rawls (1955). For a practice-dependent approach to justice, see Sangiovanni (2008).

17 For a discussion, see Hindriks (2009, pp. 253-275). 


\section{Emanuela Ceva}

18 For a more extensive discussion, see Waldron (2012b).

19 This reading is suggested by Michael Rosen (2012, pp. 94-97) in his commentary Waldron's discussion of dignity.

\section{References}

Arneson, RJ 1993, 'Democratic rights at national and workplace levels', in D Copp, J Hampton \& JE Roemer (eds.), The idea of democracy, Cambridge University Press, Cambridge.

Beitz, C 1989, Political equality, Princeton University Press, Princeton.

Ceva, E 2012, 'Beyond legitimacy: can proceduralism say anything relevant about justice?', Critical Review of International Social and Political Philosophy, vol. 15, no. 2 , pp. 186-89.

Ceva, E 2016, Interactive justice. a proceduralist approach to value conflict in politics, Routledge, New York.

Christiano, T 2008, The constitution of equality, Oxford University Press, Oxford.

Elster, J 1982, 'Sour grapes', in A Sen \& B Williams (eds.), Utilitarianism and beyond, Cambridge University Press, Cambridge.

Elster, J 1999, 'The market and the forum: three varieties of political theory', in J Bohman \& W Rehg (eds.), Deliberative democracy: essays on reason and politics, MIT Press, Cambridge.

Emmet, D 1966, Rules, roles and relations, MacMillan, London.

Estlund, DM 2008, Democratic authority. a philosophical framework, Princeton University Press, Princeton.

Feinberg, J 1970, 'The nature and value of rights', Journal of Value Inquiry, vol. 4, no. 4 , pp. $243-57$.

Fuller, LL 1969, The morality of law, revised ed., Yale University Press, New Haven.

Griffin, C 2003, 'Democracy as a non-instrumentally just procedure', Journal of Political Philosophy, vol. 11, no. 1, pp. 111-21.

Gustafsson, M. 2004, 'On Rawls's distinction between perfect and imperfect procedural justice', Philosophy of the Social Sciences, vol. 34, no. 1, pp. 300-5.

Hampshire, S 1999, Justice is conflict, Duckworth, London.

Hart, HLA 1961, The concept of law, Clarendon Press, Oxford.

Hindriks, F 2009, 'Constitutive rules, language, and ontology', Erkenntnis, vol. 71, no. 2 , pp. $253-75$.

Hobbes, T 1985, Leviathan, Penguin Books, London.

Kramer, MH 1997, 'Justice as constancy', Law and Philosophy, vol. 16, no. 3, pp. 561-80.

Lyons, D 1973, 'On formal justice', Cornell Law Review, vol. 58, no. 5, pp. 833-61.

May, L \& Morrow, P (eds.) 2012, Procedural justice, Ashgate, Burlington.

Meyerson, D 2015, 'The moral justification for the right to make full answer and defence', Oxford Journal of Legal Studies, vol. 35, no. 2, pp. 237-65.

Miller, D 1999, Principles of social justice, Harvard University Press, Cambridge.

Napier, JL \& Tyler, TR 2008, 'Does moral conviction really override concerns about procedural justice? A re-examination of the value protection model', Social Justice Research, vol. 21, no. 4, pp. 509-10.

Nelson, W 1980, 'The very idea of pure procedural justice', Ethics, vol. 90, no. 4, pp. 502-11. 
Nussbaum, M 2006, Frontiers of justice: disability, nationality, species membership, Harvard University Press, Cambridge.

Rawls, J 1955, 'Two concepts of rules', Philosophical Review, vol. 64, no. 1, pp. 3-32. Rawls, J 1971, A theory of justice, Oxford University Press, Oxford.

Resnick, D 1977, 'Due process and procedural justice', in JR Pennock \& JW Chapman (eds.), Due process, vol. 18 of Nomos, New York University Press, New York.

Rosen, M 2012, 'Dignity past and present', in J Waldron (ed.), Dignity, rank, and rights, Oxford University Press, Oxford.

Rosenfeld, M 1998, 'A pluralist critique of contractarian proceduralism', Ratio Juris, vol. 11, no. 4, pp. 291-319.

Sangiovanni, A 2008, 'Justice and the priority of politics to morality', Journal of Political Philosophy, vol. 16, no. 2, pp. 137-64.

Searle, JR 1969, Speech acts: an essay in the philosophy of language, Cambridge University Press, Cambridge.

Searle, JR 1995, The construction of social reality, Penguin, London.

Sen, A \& Williams, B (eds.) 1982, Utilitarianism and beyond, Cambridge University Press, Cambridge.

Thibaut, J \& Walker L 1975, Procedural justice: a psychological analysis, Erlbaum, Hillsdale.

Tyler, TR 1988, 'What is procedural justice?: criteria used by citizens to assess the fairness of legal procedures', Law \& Society Review, vol. 22, no. 3, pp. 103-35.

Waldron, J 1999, Law and disagreement, Oxford University Press, Oxford.

Waldron, J 2012a, 'How law protects dignity', Cambridge Law Journal, vol. 71, no. 1, pp. 200-22.

Waldron, J 2012b, Dignity, rank, and rights, Oxford University Press, Oxford.

Waldron, J 2013, 'Political theory: an inaugural lecture', Journal of Political Philosophy, vol. 21, no. 1, pp. 1-23. 